Society), Dr. Franklin Parsons, Mr. Daydon Jackson (Secretary of the Linnean Society), Mr. J. E. Harting, Dr. Bowdler Sharpe, Mr. J. Britten, Mr. E. Saunders, Colonel Swinhoe, Mr. A. W. Bennett (Vice-President of the Linnean Society), Mr. Percy Sladen (Secretary of the Linnean Society), Mr. D. Morris, Mr. Miller-Christy, and by a large number of other Fellows of the Linnean, Geological, Zoological, and Entomological Societies of London; and by the editors of the Geological Magazine, the Tournal of Botany, the Zoologist, the Entomologists' Monthly Magazine, and the Entomologist. Herbert Goss.

Linnean Society, Burlington House, W., February 6.

\section{ON THE NEW STAR IN AURIGA.}

$\mathrm{W}^{\mathrm{E}}$ were enabled last week to make an announcement of the discovery of a new star in the constellation Auriga, as we received on Wednesday the Edinburgh Circular giving an account of the manner in which the first information had been received. A telegram was sent by Dr. Copeland to the Astronomer-Royal on the date of the reception of the post-card-Monday, February I-and, as we have since learnt from the Astronomische Nachrichten, a telegram was also sent by Dr. Copeland and the Astronomer-Royal to Kiel. Unfortunately there is at present in England no local system for the distribution of astronomical intelligence of this character, so that it will probably be found that the fine night of Monday was only devoted to observations of the new star in a very restricted number of Observatories. The necessity for correcting this state of things has been pointed out by Mr. Lockyer in the Times of Friday, and it is to be hoped that some steps may be taken to rectify the defect. As it turns out, however, no very great harm has been done, for the new star, instead of degrading its light rapidly from the day of its discovery on February I, seems if anything to have brightened, so that the changes in its light between Monday and Wednesday were probably not so great as those observed in Nova Cygni during the first two or three days of its visibility.

A telegram from Prof. Pickering communicated by the Astronomer-Royal to the Times of Monday seems to show that the star, instead of bursting forth suddenly about the date when the anonymous post-card was sent to Dr. Copeland, has really been visible since last December, perhaps even for a longer time; but in any case it has not been registered in any recognized Catalogue. Prof. Pickering states that he finds this star visible on three plates belonging to the series of the Draper photographs at different dates during the month of December. The telegram through the "Centralstelle fuir Astronomische Telegramme," Kiel, runs as follows:- "Copeland's Nova bright on photograph December Io, fain December I ; maximum December 2o; spectrum unique. -PICKERING." It would thus appear that Prof. Pickering had photographed the new star on the three dates named in the course of the photographic mapping of stars and their spectra which he is carrying out at Harvard College Observatory. We do not yet know whether the plates were examined at the date on which they were taken, or whether the telegrams relating to the appearance of the Nova may have caused an examination to be made, but the spectrum was visible on all three plates.

As we stated last week, the observations in England commenced on Monday night at Edinburgh, on which date Dr. Copeland saw bright lines, and at the Royal Observatory on the same evening, when the new photographic 13 -inch refractor was used for determining the exact position of the star. With this fire instrument the Astronomer-Royal was able to detect that the star differed from the other stars on the plate in appearance.

As to the work on Tuesday night, at present we know nothing. An announcemient of the discovery appeared in the Times of Wednesday, on which date also, as we have already stated, Dr. Copeland's Edinburgh Circular was received in London. On that night, therefore, which happened to be fine, observations we commenced at South Kensington, and two photograpis were obtained, together with some eye-observations, which were communicated to the Royal Society by Mr. Norman Lockyer on the next day in a preliminary note, from which we make the following extracts :-

"Last night was fortunately fine, and two photographs were taken of the spectrum-the first exposed from 7.30 to 9 , or for $\mathrm{Ih}$. $3 \mathrm{Om}$.; the second exposed from 9.30 to $\mathrm{I} 2.30$, or for $3 \mathrm{~h}$. om. The first registered 13 lines; the second appears to contain some additional ones, but they are very faint, and have not yet been measured.

"A complete discussion of these pho ographs will form the substance of a subsequent communication, but already the following approximations to the wave-lengths have been obtained, the photographs being treated absolutely independently, means, however, being taken for the four least refrangible lines, as there has not yet been time to construct a proper curve for this regior :-

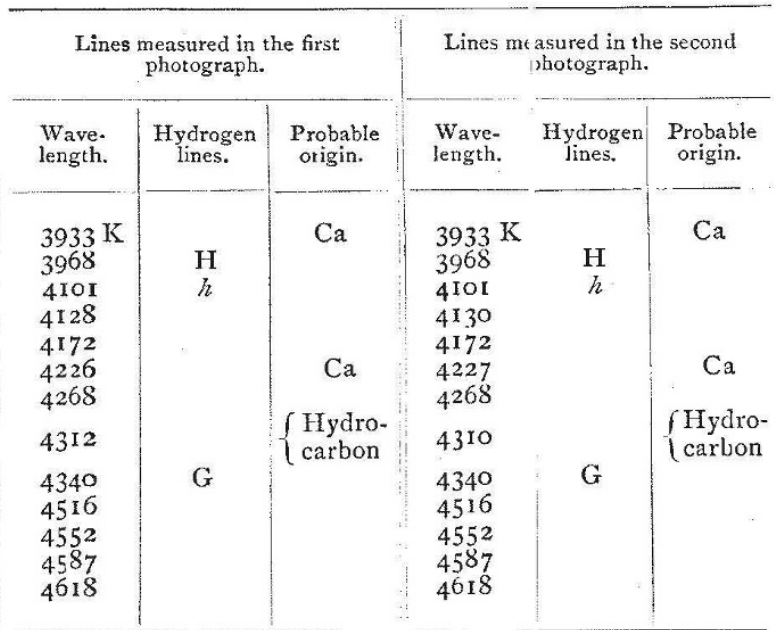

"I have recently taken up the question of stellar spectra. and find that a 6 -inch object-glass with a prism in front of it is all that is required for the br ghter stars. This instrument was employed upon the Nova, which is of about the fifth magnitude, so the exposures were necessarily long.

"For the eye-observations, the new -foot mirror which has recently been presented to the Astro-Physical Laboratory by Mr. Common was employed, but unfortunately the clock is not yet mounted, so that the observations were very difficult.

"C was the brightest line observed. In the green there were several lines, the brightest of which was in all probability $F$, the position being estimated by comparison with the flame of a wax taper. Another line was coincident-with the dispersion employed-with the radiation at wave-length 500 from burning magnesium wire. A fainter line between the two last-named was probably near $\lambda 495$, thus completing the trio of lines which is characteristic of the spectra of nebulæ. There was also a fairly bright line or band coincident with the edge of the carbon fluting at $\lambda 517$ given by the flame of the taper. A feeble line in the yellow was coincident under the conditions employed with the sodium line at $D$.

"The hydrogen line at $G$ was distinctly seen, as well as a band, or group of lines, between $\mathrm{G}$ and $\mathrm{F}$.

"Nearly all the lines appear to be al proximately, if not actually, coincident with lines seen in the various types of Cygnus stars, the chief difference being the apparent existence of carbon, hydrocarbon, and calcium in the Nova.

No. I 163 , VOL. 45$]$ 
"The colour was estimated by Mr. Fowler as reddish yellow, and by Mr. Baxandall as rather purplish. My own impression was that the star was reddish, with a purple tinge. This was in the ro-inch achromatic. In the 3 -foot reflector it was certainly less red than many star of Group II. No nebulosity was observed either in the 3-foot or the 10-inch refractor, nor does any appear in a photograph of the region taken by a $3 \frac{1}{2}$-inch Dallmeyer lens with three hours' exposure. It should be stated that the camera was carried by the photographic telescope, the clock of which had had its normal rate purposely changed to give breadth to the spectrum.

"The photographs were taken and reduced by Messrs. Fowler and Baxandall. The eye-observations and comparisons were made by Mr. Fowler."

The nights of Thursday, Friday, and Saturday were hopelessly bad, but on Sunday night the weather cleared, and more photographs were taken at South Kensington, an account of which, we believe, has been communicated to the Royal Society. Observations of the Nova are therefore well in hand, and there is no doubt that a comparison of the photographic plates obtained in December and February will provide us with much minute information regarding the behaviour of our new visitor.

The remark in Mr. Lockyer's communication to the Royal Society, that the spectrum of the star contained nearly all the lines visible in the stars in Cygnus, is one of considerable interest and importance, because, if it be confirmed by subsequent observations, it will show that these stars in Cygnus cannot be stars in the true sensethat is, bodies like our sun. This seems pretty evident from the fact that their spectroscopic phenomena can be reproduced by another body which suddenly appears, and probably will rapidly become invisible. The idea that any of these bodies are "worlds on fire," as was once thought, need now no longer be discussed.

\section{MR. TESLA'S LECTURES ON ALTERNATE CURRENTS OF HIGH POTENTIAL AND FREQUENCY.}

$\mathrm{I}^{\mathrm{T}}$ is not often that the outward and visible signs of a great scientific success are so prominent as they were last week at the Royal Institution. The reports which have reached this country of the work of $\mathrm{Mr}$. Nikola Tesla have made his name known to those who are watching or aiding the progress of electrical science. $\mathrm{He}$ was recently invited by the Institute of Electrical Engineers to lecture before it, and the interest which his coming excited spread in widening circles as the day on which he was to exhibit his experiments drew near.

It was evident that the ordinary meeting-room of the Institute would be too small, and the Managers of the Royal Institution placed their theatre at its disposal. Members of the Royal Institution, were, however, anxious to hear and see for themselves; and finally $\mathrm{Mr}$. Tesla consented to lecture on two consecutive nights to the Institute and the Institution respectively.

On both occasions the room was full; on the first it was overflowing. Gathered round the lecture table was a crowd of those whose business it is, either as theorists or as practical men, to keep abreast of the wave of scientific advance ; but as the youthful lecturer -who looks even younger than his years-with a modesty and charm of manner which were altogether irresistible, showed wonder after wonder, the interest of this critical audience deepened into enthusiasm. The speaker's broken English and imperfect explanations did not detract from his success. His marvellous skill as an experimentalist was evident and unmistakable, and his hearers left the room convinced, not only that another step forward has been taken, but also that in NO. I $[63$, VOL. 45 ]
Mr. Tesla we have a scientific explorer, who, if health and life be granted him, will travel fast and far.

Briefly, Mr. Tesla has done much to attain the continuous stream of electrical oscillations which Prof. Fitzgerald, at a recent meeting of the Physical Society, compared to a continuous whistle. The oscillations which Hertz studied die out almost instantaneously. Could they be mairtained, a practically new weapon would be placed in our hands. Tesla does not, indeed, maintain them, but he renews them many times per second, and the results are marvellous.

Though the potential is enormous, the electrode of the apparatus can be safely handled. If a person in conducting communication with it touches a vacuum bulb or tube it glows, and if the tube is brought near to others it sets them a-glowing too. No return is needed, the current is completed through surrounding space. The phosphorescent materials in some of the beautiful tubes lent by Mr. Crookes shone brightly when one electrode only was connected with the coil. If the terminal is surrounded by an aluminium tube, the glow is notably increased. The experiment of making a vacuum-tube luminous by simply holding it in an oscillating field was successfully performed, and the lecturer himself received with impunity a crackling discharge, some six or eight inches in length, by holding his hand at that distance from the terminal of his coil.

All these things are not merely wonders. Mr. Tesla is working with an object. $\mathrm{He}$ is one of those who hold that a phosphorescent glow is the light of the future. $\mathrm{He}$ hints at artificial auroræ spreading from the summits of towers of hitherto undreamt-of height, and he has at all events got as far as producing in air at atmospheric pressure a glowing plane bounded by two rings about a foot and thirty inches in diameter respectively. Whether his visions will all be realized may be doubtful. There is is no doubt that they are guiding him aright. As Lord Rayleigh said in moving the vote of thanks, a door has been opened into a new region of inquiry, into which Mr. Crookes and Mr. Tesla have entered almost alone.

Those who some fifteen months ago heard Prof. Hertz acknowledge in terms of genuine emotion that he had built upon a foundation laid by Englishmen, that Englishmen had first recognized the importance of his work, and that from England its first reward had come, must have listened with pleasure when the part that this country has taken in the development of electrical science was referred to in a like appreciative tone by Mr. Tesla. It is not indeed that the achievements of our great electricians are bettered or rendered more important by acknowledgment, but it is pleasant to note how cosmopolitan science is becoming, and that among scientific workers the feeling of fellowship is overcoming that of rivalry. For the rest we can only congratulate Mr. Tesla alike upon his work and his reception, and the scientific world on the exhibition of a number of beautiful experiments which will afford food for useful reflection to theorist and experimenter alike.

A. W. R.

The announcement of Mr. Nikola Tesla's lecture to the Institution of Electrical Engineers excited widespread interest among all in the least degree interested in electrical science. The succession of almost marvellous experiments in which in great measure it consisted must have gone far beyond the anticipations of the most sanguine of those of the audience who had had no previous account of the nature and results of his work. It is not too much to say that the Royal Institution lectures mark a distinct epoch in the progress of theoretical and applied electricity. While, on the one hand, the experiments which the lecturer showed seemed to point to a possible revolution of our methods of electric lighting, on the other hand they must have suggested, if not for the first 